\title{
Introduction: Beyond borders: Extending the relevance and impact of creative and entrepreneurial action
}

\section{Lynn Book and David P. Phillips}

The question What is creativity? defies singular definition. In this introductory chapter, we address its complex and diffuse nature, and show that its meaning and purpose depend on the disciplinary discourses with which it is aligned and the cultural domains in which it occurs. It takes form in human behavior as cognition and action; it can be located in objects, processes and systems; and it emerges in collaborative groups and virtual networks (Sawyer, 2003). It is full of contrasts, often requiring conflict stimulus, while also inducing empathic responses in both producers and receivers (Bannerman, 2007; Sternberg, 2007). Moreover this chapter demonstrates that high-order creative engagement pivots on transformation - of the individuals, objects and environments involved (Becker, 2009; Csikszentmihalyi, 1996; Sullivan, 2005).

Creativity theorists have defined the term as "the ability to produce work that is novel (i.e., original, unexpected), high in quality, and appropriate (i.e., useful and meeting task constraints)' (Sternberg et al., 2002). Public perceptions of creativity tend to narrowly define it as specialized behavior that results in a product or artifact unique to the arts and contingent on genetic predisposition, or talent. These and other creativity 'myths' (Sawyer, 2008) have the power to arrest the imagination of the artist and non-artist alike. Further, culturally constructed and socially accepted forms of creativity can hinder attempts to develop more encompassing ideas of what it can be (Csikszentmihalyi, 1996; Sternberg et al., 2006; Sternberg, 2007).

In contrast to creativity, the definitions and purpose of entrepreneurship appear straightforward. The shorthand definition in wide use is 'the pursuit of opportunity without regard for resources currently controlled' (Stevenson, 1983), but leading experts, such as Donald Kuratko (2008), have expanded it to include 'morally conscious approach[es] to business'. It has also been more openly defined as 'a kind of behavior that includes: 
(1) initiative taking, (2) the organizing and reorganizing of social mechanisms to turn resources and situations to practical account, and (3) the acceptance of risk or failure' (Hirsch et al., 2005).

This brief review of scholarly definition and public perception shows that old ideas and assumptions are dissolving as leading-edge research and practice in a twenty-first-century global context expands our thinking, inspires new action, and reshapes moral purpose. Creativity is no longer tied to traditional arts and design, although we should value and study carefully their histories, philosophies and methodologies (Book, 2008; Sawyer, 2008; Tepper and Kuh, 2011). The arts conservatory is in transition and increasingly giving way to new practices, such as collaboration with underserved communities. Another significant trend is found in the design sector, where missions are being redefined and creative labor redirected to include co-evolved cultural projects and entrepreneurial ventures (Becker, 2009; Smith, 2007, 2011; Sullivan, 2005). In similar ways, business interests are responding to tremendous external pressures to shift the historic priority of corporate and stakeholder welfare to more conscientiously serve the common good. Still widely seen as a variation of a traditional business model, entrepreneurship is pushed to jettison first-world terms focused solely on pursuits driven by individual achievement and wealth creation (Bornstein, 2007; Peters, 2009) and to retool its aims in relation to sociocultural context and need (Raunig et al., 2011). It is also being challenged to move beyond applied approaches that instrumentalize its acts and products and develop new ways to critically engage creative principles and methods (Peters, 2009). Simultaneously external pressures are influencing the academy to educate students in creativity and the development of innovative social enterprises (Baumol, 2010).

In this environment of change and challenge, the meaning and import of creativity and entrepreneurship grow to embrace quality of engagement, responsiveness to context and accountability for consequences. Terms and aspects are being renovated as broad-spectrum, dynamic, interresponsive human behaviors with tremendous generative and adaptive capacity and scope. Innovation, a type of creativity, is readily associated with entrepreneurship in that it has more measurable economic value. Like invention, it is generally sited in commercial, technological and scientific spheres and where it is relatively quantifiable and therefore more fundable. The global development of social entrepreneurship and microenterprise is bringing change by producing hybrid for- and not-for-profit initiatives under the rubric 'doing well while doing good'.

As new higher education programs develop, more faculty across disciplines are called to integrate teaching and research expertise and to create 
bridges between private and public engagement (West et al., 2009) with renewed moral purpose (Jackson, 2006). While relying, like creativity, on a combination of theory and practice in teaching, entrepreneurship has been most concerned with practical applications. Creativity has a more substantial body of theory and research but has been dominated by psychology and therefore remained somewhat specialized. Increasingly, these areas are being reshaped by new theory, innovative research, teaching and other activities that blur the boundaries of disciplines, professions and cultures. Crossover and combined laboratories, studios, networks and centers are on the rise and provide 'in-between' spaces for new knowledge production, economic revitalization and community redevelopment. Given these and other changes, accelerating due to urgent circumstances, institutions and industries must develop new flexible research modes and responsible partnership covenants across all sectors (Edwards, 2008).

Leading-edge creativity/entrepreneurship models bridge the arts and sciences within the academy and partner with social sectors; for example, art/science spaces such as The Laboratory at Harvard and Le Laboratoire in Paris, both founded and directed by Harvard University's David Edwards $(2008,2010)$, a biomedical engineer, social entrepreneur and creative writer. Another example of border-crossing is the Center for Design Innovation in Winston-Salem, a University of North Carolina satellite institute with a certain amount of autonomy to develop novel public engagement and regional economic initiatives while pursuing the mission of its parent affiliation. Other efforts, like PETLab at Parsons The New School of Design in New York or D-Lab at the Massachusetts Institute of Technology in Boston, are establishing international programs where students have direct collaborative encounters with communities in need around the world. These initiatives are renovating definitions by developing novel practices in hybrid spaces to address complex, realworld problems. They spark individual potential and inspire the public imagination with new forms and purposes for creativity, innovation and entrepreneurship.

Some of the most compelling examples of collaborative creativity and purposeful entrepreneurship develop through some of the most fruitful and unlikely alliances. The fields of entrepreneurship and creativity and the related areas of design and innovation are not only expanding definitions and practices within fields and domains but also enlarging the meaning of a citizenship that is both local, and globally interconnected.

Within these currents of change, we are beginning to see where creativity and entrepreneurship intersect. But how do their intersections work productively with inherent tensions to advance critical insight and social innovation? In these chapters, contributors view creativity and 
entrepreneurship, separately and together, as human knowledge and action that (1) challenge and disrupt conventional structures or domains; and (2) lead to positive transformations in people, institutions, cultures and societies. They focus on the ways their interactions can catalyze ideation methods (creative processes) and social venture creation (entrepreneurial processes). They advance the scholarship on these subjects by challenging domain-specific approaches (Plucker and Beghetto, 2004). They problematize the pairing of creativity and entrepreneurship (Raunig et al., 2011) and extol its constructive potential, qualities of imagination and risk that lead to radical improvements for individual and public good (Bornstein, 2007; Craft et al., 2007; Edwards, 2008).

In locating productive tensions within this discourse, the editors aim to extend the dialogue as a necessary stage in building programs, transforming institutions and bettering society (Long Lingo and Tepper, 2010; Sawyer, 2008; Tepper, 2004). To that end, each contributor is an interdisciplinarian or starts from an interdisciplinary perspective in research and projects that bring new focus to creative engagement or use entrepreneurship as an entry point to examine creativity. The text as a whole is an example of an interdisciplinary repertoire that is alive, complete with the biases and cultural assumptions of the present moment (Taylor, 2003). The projects and proposals described here are ongoing and immediately relevant not only to the contemporary milieu but also to future societies.

In examining creativity and entrepreneurship both separately and synergistically, the book's overarching concerns are two-fold:

- How can individuals, as global citizens, foster highly creative, critically active and socially accountable practices to co-create a just and imaginative world?

- How can creativity and entrepreneurship animate institutional and social bodies to build a humane, vivid and interdependent world?

Today's teachers, practitioners and leaders are charged with addressing these questions in order to make sense of creativity and entrepreneurship within and beyond conventional borders. To transform research and teaching practice, to build new educational and public bodies, the approach must be robustly interdisciplinary and spring from inventive models of theory and practice. Are the entry points practicable behaviors that deeply connect individuals with their milieu in complex, interdependent ways? Are they pivot points, on which regions can reinvent themselves as 'creative economies' (Araya and Peters, 2010; Florida, 2002; Raunig et al., 2011)? These and other crucial questions are at the heart of the inves- 
tigations presented here. Together, the authors challenge themselves and readers to participate in the future with critical imagination and conscious action in the present.

Interdisciplinarity requires interrelating research and enlarging expertise across domains and knowledge areas to develop innovative synthesis (Plucker and Beghetto, 2004) and comprehensive understanding (Hennessey and Amabile, 2010). The ways that we engage complex disciplinary and cultural networks are crucial to meeting the challenges of a world in rapid flux. To sustain relevance, we must develop the ability to critique our efforts and sharpen wisdom gained through experience and experimentation (Craft et al., 2007) as we teach, create, collaborate, launch, commune, guide and govern (Long Lingo and Tepper, 2010; Sternberg et al., 2006).

Navigating the expanding boundaries and permeable practices of creativity and entrepreneurship across multidisciplinary and cultural domains can be difficult. Scholars and practitioners are challenged by the sheer accumulation of theories and approaches. Important bodies of knowledge have been developed, distinguished by research innovations and investigated in novel sites, but researchers have yet to integrate them. In a 2010 report on creativity in higher education, psychologists Teresa Amabile and Beth Hennessey underscore the need for a systems approach to formulate broad-spectrum theories of creativity. They propose that 'researchers recognize that creativity arises through a system of interrelated forces operating at multiple levels, often requiring interdisciplinary investigation'. Research on developing creativity highlights the need for mechanisms, not only to examine best practices, but also to formulate new investigations that combine theory and practice, reflexive and active methodologies that draw from a range of disciplinary and cultural domains (Edwards, 2008; Jackson and Shaw, 2006; Sullivan, 2005). Such combined research approaches will elucidate the inherently inter-, trans-, and even extradisciplinary characteristics of creativity (Becker, 2009).

In pursuit of this goal, editor Lynn Book organized a 2009 national symposium, Creativity: Worlds in the Making, at Wake Forest University (Sternberg et al.). It was one of the first in the US to gather a multidisciplinary and culturally rich group of scholars, visionaries and activists to consider creativity as it relates to traditional disciplines, emerging studies, such as entrepreneurship, and new practices in the social sphere. Specifically, this highly charged, dynamic forum drew several hundred scholars, artists, scientists, public sector administrators and others who presented papers, conducted interactive sessions, developed novel exchanges and staged events based on contemporary art practices. Several contributors were targeted for this collection, and later, other 
voices with significant expertise in either creativity, entrepreneurship or both were selected for inclusion as well. Book organized a second, smaller conference in 2011, Teaching Creativity in Higher Education: Current Trends and Critical Encounters (http://entrepreneurship.wfu.edu/ creativity, accessed 30 November 2012), to identify coherence in the ways that creativity scholarship and teaching were unfolding and to enable leading voices in institutional and cultural arenas to develop programs and initiatives aligned with new pedagogical imperatives.

Both conferences corroborated current research and practice, reframing creativity as inherently interdisciplinary and cross-sectoral, and identifying the need for critical and conscious approaches to it. They also addressed entrepreneurship as a particularly able partner for creativity and an important mechanism for social change. What became abundantly clear was that well-established paradigms that protect current knowledge domains are not only being challenged from within but are also already shifting with institutional and societal pressures generated by the global expansion of information, capital and competition (Florida, 2002; Long Lingo and Tepper, 2010; Tepper, 2004). Innovative work by scholars and practitioners in educational and cultural settings is collectively responsible for transforming perspectives on creativity, moving us far beyond the models originally developed in the field of personality psychology or traditional fine arts. Perspectives on entrepreneurship are also moving swiftly away from the narrow context of Western business conventions and toward an ethics of consequence (Bornstein, 2007; Edwards, 2008).

Pressing questions for leaders in education include whether and how to make creativity and entrepreneurship explicit in curricular and institutional planning and development and how best to provide strategic support for sustained faculty engagement and research in these areas (West et al., 2009). Leaders in the public sphere have corollary concerns about how to balance ethics with economic development in creativity and entrepreneurship initiatives and programs that have the potential to be socially and culturally transformative (Araya and Peters, 2010; Florida, 2002). With global competition on the rise, the bottom line often dictates just how creative or entrepreneurial the next decision will be. Disciplinary paradigms, institutional biases, economic imperatives and public policies all implicitly and explicitly dictate how creativity and entrepreneurship should be taught, learned and practiced (Peters, 2009; Raunig et al., 2011). Adventurous teachers, researchers and global citizens are challenged to use the friction between creativity's freedom and methodological specificity, and entrepreneurship's pragmatism and commercial rapaciousness so as to enable inventive, collaborative and sustainable responses to 
twenty-first-century imperatives (Araya and Peters, 2010; Baumol, 2010; Edwards, 2008, 2010).

Higher education is a primary social arena shaping societal values, public policy and economic systems. Historically, the impetus to develop creativity pedagogy has largely come from individual faculty, whose disciplines determine how courses and research are oriented. Entrepreneurship pedagogy is generally taught by professors of practice at university business schools, even when a course or program is located in the liberal arts college (West et al., 2009). As curricular and institutional inter-, trans- and postdisciplinary initiatives grow, more creative approaches to sharing knowledge and expertise, particularly in the liberal arts, are needed to build momentum for conceptual and structural reinvention. We need a critically creative pedagogy that works adroitly with many areas of knowledge to challenge assumptions and combine perspectives and strengths, but its development is demanding and hard to sustain, and effects beyond the classroom can be limited. Because of evolving and disparate scholarship and the challenges of assessment, articulating a compelling rationale for creativity and entrepreneurship curricula remains both intimidating and essential (Araya and Peters, 2010; Long Lingo and Tepper, 2010; Sternberg, 2007; Tepper, 2004; West et al., 2009).

In addition, academic deans and department chairs may resist any revamping of disciplinary domains and practices, even as administrative powers, driven by economic and other exigencies, push for changes. Avenues to curricular, institutional and cultural change may be predetermined by a director or administrator's desire to stimulate faculty research with specific goals in mind, including attracting a more diverse student population or building a national reputation. The findings of the contributors to this volume demonstrate that, in contrast to such approaches, combined diverse strategies are needed to enlist motivated faculty, receptive departments, supportive administrators and community voices. While the level of commitment to new academic initiatives, business ventures and community reinvestment will vary, providing dedicated support and appropriate structures for experimentation in the academic realm and robust intercultural and transmedia modes of creativity and entrepreneurship in the public sphere is crucial. The need to inspire fresh thinking and to catalyze change for social good cannot be understated (Araya and Peters, 2010; Becker, 2009; Bornstein, 2007). 


\section{ORGANIZATION OF PARTS AND CHAPTERS}

Here, we present a collection of chapters by diverse experts who teach, conduct research, administer, direct and lead in academia, the business world, the arts, sciences and public policy. Cumulatively, their work creates a topology of innovative research and emergent practices that are particular to creativity and entrepreneurship and can also be broadly translated and applied across all areas of education and public life. Each contribution, in its own way, articulates and proposes conceptual and structural reinvention for how we live, work and imagine together. We believe this book will serve as an important resource, stimulating progressive and integrative discussion, research, programs and ventures. To facilitate understanding, each Part of the book is organized around current themes in the development and deployment of creativity and entrepreneurship in academic and public contexts. We hope that these examples of empathic leadership, imaginative citizenship and visionary stewardship lead to constructive action (Craft et al., 2007).

Part I, 'Reimagining higher education: creative experiments in teaching and learning', explores models for incorporating creativity and entrepreneurship in higher education curricula and program development, and applying them to organizational structures. The chapters focus on faculty/ student engagement and faculty/administrative behaviors and novel partnerships in and out of the academy.

Lynn Book's chapter focuses on creative practices in higher education and their pairing with entrepreneurship studies in teaching, research and engagement. She calls for a critical creativity that is transdisciplinary, heuristic, ethical and multimodal to awaken transformative vitality in knowledge- and culture-making.

In the next chapter, Liora Bresler examines the ambitions and tools of the intellectual entrepreneur, identifying faculty teaching and research processes that can lead to institutional change. She stresses experiential learning as a site of cross-fertilization for educators, scientists, artists and scholars.

Heidi LaMoreaux describes a crossdisciplinary model for a natural science curriculum that dismantles the misleading and often discouraging dichotomy between science and personal expression to inspire undergraduates toward wholly new, hybrid observations and connections through hands-on projects. She demonstrates how a theory of soil formation and the basic principles of scientific cores can provide structural and even narrative cues for a deeper understanding of identity formation.

David P. Phillips presents case studies in support of social entrepre- 
neurial strategies to foster creative interdisciplinary academic communities guided by public discourse.

Part II, 'Disciplinary immigrants: strategies in creative process and practice', examines the interrelationship between creative process and cultural practice and opportunities for applying creativity in contexts outside of higher education. Fresh thinking on both highly individuated and public learning and exchange environments connects conceptual and concrete methods to prepare creative thinkers, practitioners and entrepreneurs.

Michele Root-Bernstein looks at worldplay - detailing an imaginary place to reconceive conventional ideas and to test radically new ones. Developing imaginative skills at the individual level enables resourcefulness in public life.

An educator in clinical neuroscience and physical therapy, Glenna Batson introduces brain mapping studies that link neuroaesthetics directly to the creative process. Starting from the notion of movement as an inherently creative act, her chapter examines dance education as a synthesis of perception, interpretation, analysis and active engagement in the world, and discusses its use, along with contemporary choreography and improvisation, in medical settings to improve balance and mobility in adults with Parkinson disease.

The chapter by Carolyn D. Roark, Kevin Daum and Mary Abrahams, 'How to develop an entrepreneur', establishes a pedagogical model for stimulating creativity and entrepreneurial thinking in industry and other settings. They believe that anyone can be taught cognitive patterns that facilitate creative thought and action, and use theater as a model with a wide range of applications.

Beth Altringer's research examines the dynamics of social interaction in team innovation, demonstrating best practices for novel project outcomes in the context of organizations and organizational behavior. She identifies two distinct approaches that optimize creative teamwork and, surprisingly, antagonistic processes that can lead to productivity.

Part II concludes with Andrew S. Yang, a biologist teaching and conducting innovative research at a contemporary arts institution. His interdisciplinary model for creativity challenges some assumptions of the biological sciences and points to new forms of engagement with art and design practices. He demonstrates that when we emigrate across disciplinary boundaries, our perspectives and the disciplines grow and change.

Part III, 'Public engagement and the duty of imagination', links roles, responsibilities and potential for individual creativity and social entrepreneurship within networks and systems. Each chapter delves into institutional structures that assist or impede public engagement and long-term collaborations. 
Marilyn S. Sarow and Bonnye E. Stuart draw from both academic and professional contexts to investigate the role of collaborative discourse in the creative process. Their expertise in speech communication, mass communication, management and marketing informs a successful model for international business education: specifically, an international business communication textbook that promotes global thinking.

A study by four neurobiology and radiology researchers, headed by Dwayne W. Godwin, gleans insights into group dynamics, territorial behaviors, human brain function and goal-directed creative behaviors from 'small-world' networks, which connect mutual acquaintances. Analyzing the hierarchy on a university campus, they identify properties that optimize or impede collaborative processes.

Musetta Durkee investigates Web 2.0 citizenry: the role of emerging technologies and the arts in sparking new forms of interaction and political identities. She posits interconnected collaborative enterprises for creative public engagement, community-building, problem-solving and decision-making.

Lyndon Rego and Philipp Essl explore the social benefits of empathy in enhancing shared work and enabling systemic change. They promote empathetic engagement in the experiential classroom to maximize outcomes through shared perspectives and constructive collaborations. Applications extend from traditional learning environments to institutional and business settings in both developed and emerging communities around the world.

The final chapter by Scott Sherman discusses the concept he calls 'transformative action' and describes the classroom techniques for successfully launching social change projects. He describes how his Transformative Action Institute created an American university initiative that has led to grassroots social entrepreneurship curricula in a variety of cultural settings around the world.

\section{CONCLUSION}

For more than a decade, creativity and entrepreneurship curricula and programming have played an increasingly significant role in business priorities, university missions and public policies in the US, Europe, Asia and elsewhere (Creative Economy Report, 2008; European University Association, 2007; Florida, 2002; Long Lingo and Tepper, 2010; Sternberg, 2007; Tepper, 2004). Diverse, critical and imaginative approaches to teaching, learning and practicing creativity and entrepreneurship prove essential in navigating a postdisciplinary and transcultural 
world. Convergences and collisions between public and private, education and business settings and resourced and under-resourced areas pressure leaders in higher education and public visionaries to make ethical, futureleaning decisions (Edwards, 2008, 2010; Raunig et al., 2011; Smith, 2007, 2011).

While creativity might seem more compatible with liberal arts initiatives, it is allying with entrepreneurship studies to produce economic and social value in new ways. At the same time, entrepreneurship education is incorporating such aspects of creativity as design and innovation in order to meet social and resource imperatives. The time for critical reorientation of our academic and operational models is now. Unorthodox partnerships among institutions, social networks, organizations, businesses, public policy-makers and governing bodies are needed for relevance and advancement.

The comprehensive reach of these chapters articulates research findings and resources that will help readers to deploy new perspectives and to lay the groundwork for action that embraces sociocultural imperatives (Bornstein, 2007; Edwards, 2008; Sawyer, 2008). New and countervailing views demonstrate that creativity and entrepreneurship studies and action in a wide range of entwined contexts, especially higher education and sustainable global development, must be based on imaginative, critically engaged and accountable theories, structures and practices. The prevailing 'human-centered' creativity and entrepreneurship discussed here posits that local sites of production in atypical environments with radically different resources require tremendous conceptual and practical shifts. Viewed as an 'active repertoire', this collection points to the force of creative imagination in transforming untenable conditions into sustainable realities that enrich life for people and the planet (Becker, 2009; Taylor, 2003).

The contributors demonstrate not only the hybrid, interactive capacities of creative and entrepreneurial behaviors but their broad relevance in negotiating dynamic social change. They position ethical concerns to enlarge values propositions and propose inventive forms of qualitative research, teaching and collaboration to enrich the highly fluid and fecund state of the discourse. We invite reading across sections and chapters. We urge readers to develop responsive research and practice agendas that coordinate knowledge and resource sharing, and pair teaching with public engagement. Collectively and in their unique voices, our contributors seek to prepare global citizens who practice socially conscious agency in new, critically creative and entrepreneurial ways. The consensus is that imaginative actions today affect our co-creation of a just and vibrant world tomorrow - they begin with each one of us. 


\section{REFERENCES}

Araya, D. and M. A. Peters (eds) (2010), Education in the Creative Economy: Knowledge and Learning in the Age of Innovation, New York, Bern, Berlin, Bruxelles, Frankfurt am Main, Oxford and Vienna: Peter Lang.

Bannerman, C. (2007), 'Creativity and wisdom', in A. Craft, H. Gardner and G. Claxton (eds), Creativity, Wisdom and Trusteeship: Exploring the Role of Education, Thousand Oaks, CA: Corwin Press.

Baumol, W. J. (2010), The Micro Theory of Innovative Entrepreneurship, Princeton, NJ: Princeton University Press.

Becker, C. (2009), Thinking in Place: Art, Action and Cultural Production, Boulder, CO: Paradigm.

Book, L. (2008), 'Creativities: revaluation and transformation', paper prepared for invited panel at the P.A.V.E. Conference on Arts Entrepreneurship, Arizona State University.

Bornstein, D. (2007), How to Change the World: Social Entrepreneurs and the Power of New Ideas, New York: Oxford University Press.

Craft, Anna, H. Gardner and G. Claxton (2007), Creativity, Wisdom and Trusteeship: Exploring the Role of Education, Thousnd Oaks, CA: Corwin.

Creative Economy Report (2008), 'The challenge of assessing the creative economy: towards informed policy-making', United Nations Conference on Trade and Development (UNCTAD), accessed 14 August 2012 at http://archive.unctad. org/templates/webflyer.asp?intItemID $=4494$.

Csikszentmihalyi, M. (1996), Creativity: Flow and the Psychology of Discovery and Invention, New York: Harper Perennial.

Edwards, D. (2008), Artscience: Creativity in the Post-Google Generation, Cambridge, MA: Harvard University Press.

Edwards, D. (2010), The Lab: Creativity and Culture, Cambridge, MA: Harvard University Press.

European University Association (EUA) (2007), 'Creativity in higher education: report on the EUA creativity project 2006-2007', accessed 14 August 2012 at http://www.eua.be/eua-work-and-policy-area/quality-assurance/projects/ creativity.aspx.

Florida, R. (2002), The Rise of the Creative Class: And How It's Transforming Work, Leisure, Community and Everyday Life, New York: Basic Books.

Hennessey, B. A. and T. Amabile (2010), 'Creativity', Annual Review of Psychology, 61, 569-98.

Hirsch, Robert D., Michael P. Peters and Dean A. Shepherd (2005), Entrepreneurship, New York: McGraw-Hill.

Jackson, Norman (2006), 'Imagining a different world', in N. Jackson, M. Oliver, M. Shaw and J. Wisdom (eds), Developing Creativity in Higher Education: An Imaginative Curriculum, New York: Routledge.

Jackson, Norman and M. Shaw (2006), 'Developing subject perspectives on creativity in higher education', in N. Jackson, M. Oliver, M. Shaw and J. Wisdom (eds), Developing Creativity in Higher Education: An Imaginative Curriculum, New York: Routledge.

Kuratko, D. F. (2008), Entrepreneurship: Theory, Process and Practice, Cincinnati, $\mathrm{OH}$ : South-Western College Publishing.

Long Lingo, E. and S. J. Tepper (2010, 10 October), 'The creative campus: time for 
a "C" change', Chronicle of Higher Education, accessed 15 August 2012 at http:// chronicle.com/article/The-Creative-Campus-Time-for/124860/

Peters, M. A. (2009), 'Education, creativity and the economy of passions: new forms of educational capitalism', Thesis Eleven, 96 (1), 40-63.

Plucker, J. A. and R. A. Beghetto (2004), 'Why creativity is domain general, why it looks domain specific, and why the distinction does not matter', in R. J. Sternberg, E. L. Grigorenko and J. L. Singer (eds), Creativity from Potential to Realization, Washington, DC: American Psychological Association.

Raunig, G., G. Ray and U. Wuggenig (eds) (2011), Critique of Creativity: Precarity, Subjectivity and Resistance in the 'Creative Industries', Elmwood, IL: Mayfly Books, accessed 15 August 2012 at http://mayflybooks.org/.

Sawyer, R. K. (2003), Group Creativity: Music, Theater, Collaboration, Philadelphia, PA: Psychology Press.

Sawyer, R. K. (2008), Explaining Creativity: The Science of Human Innovation, New York: Oxford University Press.

Smith, C. E. (2007), Design for the Other 90\%, New York: Editions Assouline.

Smith, C. E. (2011), Design with the Other 90\%: Cities, Washington, DC: CooperHewitt, National Design Museum, Smithsonian Institution.

Sternberg, R. J. (2007), Wisdom, Intelligence, and Creativity Synthesized, Cambridge: Cambridge University Press.

Sternberg, R. J. et al. (2006), 'The Rainbow Project: enhancing the SAT through assessments of analytical, practical, and creative skills', Intelligence, 34 (4), $321-50$.

Sternberg, R. J., J. C. Kaufman and J. Pretz (2002), The Creativity Conundrum: A Propulsion Model of Kinds of Creative Contributions, Philadelphia, PA: Psychology Press.

Stevenson, H. H, (1983), 'A perspective on entrepreneurship', Harvard Business School working paper no. 9-384-131.

Sullivan, G. (2005), Art Practice as Research: Inquiry in the Visual Arts, Los Angeles, London, New Delhi, Singapore and Washington, DC: Sage.

Taylor, D. (2003), The Archive and the Repertoire: Performing Cultural Memory in the Americas, Durham, NC: Duke University Press.

Tepper, S. J. (2004, 1 October), 'The creative campus: who's no. 1?' Chronicle Review in Chronicle of Higher Education, 51 (6), B6.

Tepper, Stephen J. and George D. Kuh (2011), 'Let's get serious about cultivating creativity', Chronicle Review in Chronicle of Higher Education, 4 September, accessed 8 October 2012 at http://chronicle.com/article/ Lets-Get-Serious-About/128843/.

West, G. P. III, E. J. Gatewood and K. G. Shaver (eds) (2009), Handbook of University-Wide Entrepreneurship Education, Cheltenham, UK and Northampton, MA, USA: Edward Elgar Publishing. 
Lynn Book and David Phillips - 9780857937209 Downloaded from PubFactory at 04/26/2023 01:36:27PM via free access 